\title{
Brain death: A response to the commentaries
}

\section{Peter Singer ${ }^{1}$}

\begin{abstract}
My recent article, "The challenge of brain death for the sanctity of life ethic" (Ethics \& Bioethics (in Central Europe), 2018, 8 (3-4), pp. 153-165) elicited five commentaries. In this brief response, I clarify my own position in the light of some misunderstandings, and discuss whether the definition of death is best thought of as an ethical question, or as a matter of fact. I also comment on the suggestion that we should allow people to choose the criteria by which they wish their own death to be determined, or their organs removed to be donated to others.
\end{abstract}

Keywords: definition of death, brain death, sanctity of life, organ transplantation, Jahi McMath, Ireneusz Ziemiński, Piotr Grzegorz Nowak, Katarína Komenská, Ján Kalajtzidis, Vilius Dranseika and Ivars Neiders.

In my original article in this journal, I suggested that the concept of brain death poses a challenge for the traditional ethic of the sanctity of human life. In the light of our current knowledge about the continued functioning of the human organism after the brain itself has irreversibly ceased to function, we must either abandon the sanctity of life view, with its rule that a donor must be dead before vital organs such as the heart can be removed, or cease to take vital organs from patients who are declared dead because their brains have irreversibly ceased to function. None of the five Central European scholars who commented on my argument sought to defend the traditional sanctity of life view. Nor did any of them give serious consideration to the possibility that it is wrong to remove hearts and other organs from brain dead donors with beating hearts. One cannot generalize from so small a sample, but I cannot avoid wondering if this can be seen as a sign that, in a region in which the traditional view has long had powerful religious support, that view is no longer as universally accepted as it once was.

Before offering some brief comments on just a few of the many interesting points made in the papers I will clarify the view I am defending, because in some of the papers there appears to be some misunderstanding about that. Ireneusz Ziemiński provides an example of this misunderstanding when he states: "Singer defines human death as the death of the upper brain" (Ziemiński, 2018, p.189). I do not do that. I discuss two positions about when death occurs, both of which seem to me to have some plausibility. On the view that I spend most time discussing, I suggest that we could:

$\ldots$ draw on the present criteria for ascertaining total brain failure in order to determine, not that a patient is dead, but that the patient is eligible to be an organ donor. Such patients would be eligible because ... their lives are over, not as organisms, but as conscious beings. They will never again experience anything. In these very specific circumstances, continuing their lives beyond this point is of no further benefit to them (Singer, 2018, p. 159).

I hope it is clear that I am not saying that human beings whose brains have totally ceased to function are dead. If I were saying that, I would not say that "continuing their lives beyond this point is of no further benefit to them" because one cannot continue the life of someone who is

\footnotetext{
${ }^{1}$ University Center for Human Values, Princeton University (USA) \& School of Historical and Philosophical Studies, University of Melbourne (Australia); email: psinger@ princeton.edu
} 
already dead. If I don't think that people with no brain function at all are dead, then I am further still from thinking that people with no higher brain function are dead. My point is rather that we could return to a traditional view of death, but still say that once consciousness has been irreversibly lost, continued life has ceased to be a benefit to the subject of the life, and so it is ethically permissible to remove vital organs.

Ziemiński shows more accurate insight into my position when he writes: "Singer's goal was not necessarily to formulate a new criterion of death, but rather settling whether a living person can become an organ donor" (Ziemiński, 2018, p. 190). He then states my view as that "the end of upper brain function resulting in irreversible loss of consciousness is a necessary and sufficient condition of a patient becoming an organ donor" (Ziemiński, 2018, p. 190). That statement is broadly correct, but not entirely so. I do mention, more than once, the requirement of prior consent to organ donation (for example, Singer, 2018, pp. 161, 164) as a necessary condition, so the irreversible loss of consciousness is not a sufficient condition and of course, I accept voluntary organ donation - for example of a kidney - from a healthy living donor, so I do not regard the irreversible loss of consciousness as a necessary condition for organ donation either.

The second position I discuss may be responsible for some confusion about my account of the death of a human being. This second position is Jeff McMahan's defense of a higher brain account of the death of a human being, based on the view that we are not essentially human organisms, but rather minds or persons. It is possible to say that the irreversible loss of consciousness is the death of the person, that is, the end of the existence of the person we knew and loved, but it is a further step to say that it is the death of the human being, because this requires us to say that human beings are essentially minds or persons, and not organisms. That is not an easy step to take, because it requires us to say that anencephalic infants, who will never be conscious and so have no minds, are not human beings - even though they are the offspring of human parents, and have a normal human genome. As I have argued in my book Practical Ethics, in the context of the abortion debate, "human being" is a loose term that sometimes is used as if it means no more than "member of the species Homo sapiens" and sometimes is used as if it is equivalent to "person" or even to a being with certain moral qualities (Singer, 2011, pp. 71-75, 134-135).

Although I am willing to say that anencephalic infants are living human beings, I am also prepared to say that they fulfill the criteria for becoming organ donors (at least, with the consent of their parents). Ziemiński suggests that this is "problematic" (Ziemiński, 2018, p. 191) but I am not sure why he thinks this, given that he agrees with me that "it should be possible to harvest organs from people who are irreversibly deprived of consciousness, in order to save the lives of others" (Ziemiński, 2018, p. 194). His difficulties with my position are more ones of implementation, and as other writers also raise this point, I shall come back to it shortly.

In fact, as I have said, although I consider McMahan's view, with its insistence that we are minds and not organisms, is philosophically defensible, I think that the view most conducive to clear thinking about these issues is to stick with the traditional definition of death, in terms of the irreversible cessation of heartbeat and of the circulation of blood, and leave all the other issues when one may turn off respirators, or remove the heart and other organs - as ethical questions, with the best answer not determined solely by whether the patient is alive or dead. Virtually everyone now agrees that the decision to turn off a respirator is not dependent on a decision that the patient is dead. Few are yet prepared to take a similar view on the removal of organs.

Piotr Grzegorz Nowak says that "the fundamental meaning of 'death' is ethical" (Nowak, 2018, pp. 169, 175). Katarína Komenská appears to take a similar view when she advocates an "ethics of social consequences" and says that on this view, we "would determine the patient to be dead as 
a moral agent because of the protection of patient's life, quality of life and dying, and, last but not least, to protect his/her dignity" (Komenská, 2018, p. 206). Komenská adds that this approach puts the focus on "what is good for the patient," promoting "moral right, humanity, and dignity in the final moments of this patient's life” (Komenská, 2018, p. 206).

If in the spring a birch tree in my garden has not put out any leaves, I may wonder whether it is dead. This is a factual question, not an ethical one. Over the next few months, if I leave the tree in the ground, either green shoots will start to appear, or the branches and trunk will dry out, become brittle, and eventually, if I still do not remove it, start to rot. That will answer, beyond any possible dispute, my question about whether the tree is alive or dead. Should we believe, then, that the word "dead" has completely different meanings when I say "The birch tree is dead" and when a doctor says: "the patient is dead"?

We might, as McMahan suggests, identify a human patient - let's say it is my mother - with the person I loved and cared about, and so, if my mother should irreversibly lose consciousness, I could say that she is dead, because the person I loved and cared about has ceased to exist. There are benefits in thinking of beings with minds in this way, but it can create confusion, because my mother is also an organism, more specifically an animal of the species Homo sapiens, and this organism can continue to live even when the person I loved has ceased to exist. Ziemiński appears to recognize this when he acknowledges that "If they breathe on their own (and fulfill other physiological functions) then they can hardly be declared dead; loss of consciousness alone is not enough for a pronouncement of death" (Ziemiński, 2018, p. 197). He is surely right that most people would find it very difficult to think of someone who is breathing on their own, not connected to any machine, as dead. That is one reason why it may be better to use the same criteria for deciding when death has occurred whether the death is that of a tree, an oyster, a cat, an anencephalic infant, or a human being who has lived in full consciousness for many decades.

Ján Kalajtzidis appears to be making a similar point when he writes: "When a being has lost its ability to be a moral agent ... it dies as a person. However, the human being still exists and is labelled as a moral object" (Kalajtzidis, 2018, p. 216). This is, as Kalajtzidis suggests, an implication that might be drawn from McMahan's view, and it implies that a moral agent can cease to exist, "deathlessly." If the ceasing to exist of the moral agent does not involve a death, then this implies that we are restricting the use of the term "dead" to organisms, and not using it for the ceasing to exist of minds or persons. That seems a reasonable linguistic suggestion. On this view, we can say that moral agents, or persons, cease to exist, but we should not say that they die. So the irreversible loss of consciousness in a human organism in which the heart is still beating and the blood is circulating, is not a death but a ceasing to exist of the person. Once again, that opens the way for the ethical question of whether organs may then be removed from the living human organism. Kalajtzidis argues, on the basis of an ethic of social consequences, that they may be, because on this ethical view humanity and human dignity are primary values for such an ethic, and taking organs for transplantation from a human organism that is not a moral agent promotes these values. This argument shows that the ethics of social consequences is truly a consequentialist ethic. In this an ethic of social consequences contrasts with an ethic of the sanctity of human life, which will not permit the removal of vital organs from one human organism, even one with no prospect of consciousness, in order to save the lives of several other human organisms with good prospects of living rich and fulfilling lives.

Several authors raise practical objections to implementing the idea of permitting organs to be removed from patients who have irretrievably lost all capacity for consciousness. For example, Nowak and Ziemiński raise doubts about whether it would be possible to determine, with sufficient 
certainty, that the loss of consciousness is irreversible (Nowak, 2018, p. 170; Ziemiński, 2018, p. 197). In many cases, this would indeed be difficult; but in some instances, where we have a clear image of the brain showing that the entire cortex has turned to fluid, and there is no remaining brain structure other than the brain stem, the judgment can be made without any reasonable doubt.

Moreover, the argument from the difficulty of determining irreversible loss of consciousness in cases of higher brain death or persistent vegetative state does not necessarily lead to the conclusion that we should accept whole brain death, at least not as long as the determination of whole brain death is made by the medical tests now used all over the world. The case of Jahi McMath, described in my initial article (Singer, 2018, p. 158), shows that these tests, even when properly carried out in the most expert hands, can fail to detect the condition known as global ischemic penumbra. In this condition, the flow of blood inside the cranium is too low to support synaptic function, but is nevertheless sufficient to prevent the death of the cells. It seems that this happened with McMath, and her brain cells then recovered sufficient function so that she could, on request from her mother, move her right or left hand or foot. She cannot, it therefore appears, have irreversibly lost all consciousness. Is this a reason for halting the removal of organs from patients who have been certified as dead in accordance with the standard tests? None of the respondents to my original essay took up this issue, but it should not be ignored.

Vilius Dranseika and Ivars Neiders offer an interesting solution to the question of what criteria we should use for declaring someone dead, or for allowing vital organs to be removed. They argue that reasonable people may have different conceptions of what it is to be dead. They therefore propose that we leave the definition of death up to individuals, choosing between a range of options that include higher brain death, total brain death, and the traditional definition of death based on the cessation of heartbeat and circulation. They support this with the results of an online Lithuanian survey (Dranseika \& Neiders, 2018, pp. 182-185) showing that there was significant support for each of the three most plausible options -- higher brain death, whole brain death, and cardiopulmonary death -- both for determining death and for determining the point at which vital organs may be removed. Whole brain death had more support, both for determining death and for when organs could be removed, than either of the other plausible options, but when asked to make a decision for their own case, more of those surveyed chose higher brain death than cardiopulmonary death. When the respondents were asked to make the choice for a relative, more chose cardiopulmonary death than higher brain death. This indicates that people did not value their own life, once consciousness had irreversibly been lost, but were reluctant to make such a decision for a third party. (Whole brain death still had more support than either of the alternatives, irrespective of whether the choice was for oneself or for a relative.)

Dranseika and Neiders urge that their survey provides evidence supporting the view that the most practicable way to reform existing laws on the definition of death and the criteria for removing organs is to allow people to make their own choice (Dranseika \& Neiders, 2018, pp. 186-187). I accept that this is, for the foreseeable future, more likely to be acceptable to the general public than either of the options that I propose. The argument has some parallels with other issues in bioethics, for example, the fact that, at least in the United States, there is broader public support for legislation to permit physician aid in dying - that is, to allow a physician, on the request of a patient, to prescribe a lethal substance that the patient may take to end her or his life - rather than for legislation to permit active voluntary euthanasia. I do not really see any significant ethical difference between physician aid in dying and active voluntary euthanasia, but the former, rightly or wrongly, appeals more to respect for autonomy, and so, at least in the US, has received wider public support. 
Dranseika and Neiders' proposal resembles current law in the state of New Jersey, where McMath was taken after being diagnosed with brain death in California, except that New Jersey law only allows patients to object to being declared dead on the basis of whole brain death. So it effectively allows patients to choose between whole brain death and cardiopulmonary death, but it does not allow the choice of higher brain death. Nevertheless, as the McMath case shows, even such a limited law raises the question of who will pay for the extra life support required for those who choose the cardiopulmonary definition of death. In the case of McMath, this support was required for almost 4 years after she had been declared brain dead.

Should such costs be paid for from public funds, even though the costs are the result of a choice to reject whole brain death, and there is no prospect of any recovery of consciousness? If Dranseika and Neiders' proposal were implemented, those who think that the higher brain death criterion is the most reasonable point at which to declare death and thus withdraw life support and allow organs to be taken, might ask the same question about the cost of maintaining patients who can be ascertained to have irreversibly lost consciousness, but still have some brain stem function and so are not dead by the whole brain death criterion. This is a debate we would still need to have if we allow people autonomy in their choice of criteria for being declared dead, or for having machines turned off and organs removed.

\section{References}

DRANSEIKA, V. \& NEIDERS, I. (2018): In defense of pluralistic policy on the determination of death. In: Ethics \& Bioethics (in Central Europe), 8(3-4), pp. 179-188.

KALAJTZIDIS, J. (2018): The challenge of death and ethics of social consequences: Death of moral agency. In: Ethics \& Bioethics (in Central Europe), 8(3-4), pp. 209-218.

KOMENSKÁ, K. (2018): Death, ethical judgments and dignity. In: Ethics \& Bioethics (in Central Europe), 8(3-4), pp. 201-208.

NOWAK, P. G. (2018): Brain death as irreversible loss of a human's moral status. In: Ethics \& Bioethics (in Central Europe), 8(3-4), pp. 167-178.

SINGER, P. (2011): Practical Ethics, $3^{\text {rd }}$ ed. Cambridge: Cambridge University Press.

SINGER, P. (2018): The challenge of brain death for the sanctity of life ethic. In: Ethics \& Bioethics (in Central Europe), 8(3-4), pp. 153-165.

ZIEMIŃSKI, I. (2018): The ethical problems of death pronouncement and organ donation: A commentary on Peter Singer's article. In: Ethics \& Bioethics (in Central Europe), 8(3-4), pp. 189200. 